\title{
Initial Experience Using a Novel Reticulated Open Cell Foam Dressing with Through Holes during Negative Pressure Wound Therapy with Instillation for Management of Pressure Ulcers
}

\author{
Luis Fernandez ${ }^{*}$ Cynthia Ellman and Patricia Jackson \\ Trauma Surgical Critical Care Unit, Trinity Mother Frances Health System, TX, USA
}

"Corresponding author: Luis Fernandez, Associate Trauma Medical Director and Chief of Trauma Surgical Critical Care Unit, Trinity Mother Frances Health System, 910 East Houston St Suite 530, Tyler TX 75702, USA, Tel: +(903)593-8441; E-mail: thebigkahuna115@gmail.com

Rec date: December 11, 2017; Acc date: December 21, 2017; Pub date: December 23, 2017

Copyright: (C) 2017 Fernandez L, et al. This is an open-access article distributed under the terms of the creative commons attribution license, which permits unrestricted use, distribution, and reproduction in any medium, provided the original author and source are credited.

\section{Abstract}

Several published reviews and recommendations exist for the use of negative pressure wound therapy (NPWT) with instillation and a dwell time (NPWTi-d) in acute and chronic wounds. Specific dressings for use with NPWTi-d have also been developed, including a reticulated open cell foam dressing with through holes (ROCF-CC) that assists in removing thick wound exudate and infectious materials. ROCF-CC is especially helpful for wound cleansing when debridement is not possible or appropriate in patients.

We report our initial experiences in using NPWTi-d with ROCF-CC in patients with pressure ulcers. An algorithmic approach was used to determine appropriate treatment to reach the goals of therapy (i.e., wound bed preparation, granulation tissue formation, and removal of infectious materials). Previous therapies included honey and gauze soaked in Dakin's solution. All patients received antibiotics and debridement when possible.

Five patients ( 3 females and 2 males) received NPWTi-d with ROCF-CC (instillation of saline or a hypochlorous solution with a dwell time of 10 minutes, followed by 2-3 hours of -125 mmHg NPWT). Patient comorbidities included obesity, diabetes mellitus, hypertension, and peripheral artery disease. Mean age of patients was 65.2 years (range: 50-82 years). After an average of 6 days of therapy (range 2-9 days), all wounds treated with NPWTi-d with ROCF$\mathrm{CC}$ showed rapid granulation tissue formation.

We also noted improved removal of devitalized tissue and subsequent granulation tissue formation in patients receiving hypochlorous solution compared to patients receiving saline during NPWTi-d with ROCF-CC. All patients were eventually transferred to a skilled nursing facility. In our clinical practice, NPWTi-d with ROCF-CC provided effective and rapid removal of the thick exudate and infectious materials and promoted excellent development of underlying granulation tissue.

Keywords: Negative pressure wound therapy; Instillation; Thick exudate; Devitalized tissue; Wound cleansing

\section{Introduction}

Pressure ulcers (PrUs) are challenging complex wounds that develop due to localized injuries to the skin, particularly over bony prominences, because of pressure or when pressure is combined with shear and/or friction [1]. Although the definition and staging of PrUs was recently redefined by the National Pressure Ulcer Advisory Panel (NPUAP) in 2016 [2], there is still much debate regarding these changes among the healthcare community.

In our institution, high-risk operative patients with complex chronic wounds, such as PrUs, have been treated with a variety of dressings. Traditional dry/moist gauze wound dressings, low adherent dressings, and semipermeable films mitigate against fluid and environmental microbial penetration but allow the egress of air and water vapor. Moist occlusive dressing have been utilized, as these dressings support the inflammatory phase by creating a low oxygen tension environment (thereby increasing angiogenesis, iron metabolism, glucose metabolism, cell proliferation/survival and activating factors such as hypoxia-inducible factor-1), which has also been shown to increase the rate of re-epithelialization [3-5].

Hydrocolloids and hydrogels have also been used in our institution. Under the appropriate setting, these dressings absorb a certain amount of exudate but keep a moist environment; hydrocolloids are impermeable to air and are long-lasting but do not function well in exudative wounds. In a dry wound environment, hydrogels may be used to help promote moisture in the wound.

For highly exudative wounds, alginate dressings (a seaweed-derived non-woven fiber dressing) are typically used because of their ability to absorb copious amounts of fluid. We have also used autolytic debridement in wounds with a moist wound environment; however, this form of therapy is not capable of removing devitalized tissue as well as surgical debridement and is not an adequate replacement for sharp surgical debridement [6-8].

Negative pressure wound therapy (NPWT) is commonly used for the management of both acute and chronic complex wounds at our institution. This therapy has typically been associated with higher costs; however, several studies have shown an overall savings in direct and indirect costs, in a large part due to decreases in operating room 
Citation: Fernandez L, Ellman C, Jackson P (2017) Initial Experience Using a Novel Reticulated Open Cell Foam Dressing with Through Holes during Negative Pressure Wound Therapy with Instillation for Management of Pressure Ulcers. J Trauma Treat 6: 410. doi: $10.4172 / 2167-1222.1000410$

Page 2 of 5

(OR) visits, early wound closure for treated patients, reduced hospital stay, fewer required dressing changes (which potentially translates into lower material/manpower cost and care delivery efficiency), as well as improved limb preservation rates [9-14].

Over the years, NPWT has evolved to include the ability to instill topical wound solutions, which are then allowed to dwell directly onto the wound bed $[15,16]$. Allowing an instilled solution to dwell in the wound bed helps to cleanse the wound and the NPWT cycle helps remove solubilized contaminants, devitalized tissue, and slough [16]. Hypochlorite-based solutions [17,18] and 0.9\% normal saline [19-21] as topical instillation solutions have shown positive clinical outcomes.

A growing body of literature supports the use of NPWT with instillation and dwell time (NPWTi-d) with positive clinical outcomes and potential cost savings being reported [19-23]. Additionally, several published reviews and recommendations exist for the use of NPWTi-d in acute and chronic wounds $[15,16,24]$. Specific dressings for use with NPWTi-d have also been developed, including a reticulated open cell foam dressing with through holes (ROCF-CC) that assists in removing thick wound exudate and infectious materials [25]. ROCF-CC may be especially helpful for wound cleansing when surgical debridement must be delayed or is not possible or appropriate.

The aim of this 5-patient case series was to present our initial experience using NPWTi-d with ROCF-CC to manage large complex pressure ulcers that contained substantial areas of devitalized tissue, thick exudates, and/or yellow fibrinous slough.

\section{Methods}

An algorithm approach (Figure 1) was used to determine appropriate treatment to reach the goals of therapy (ie, wound bed preparation, granulation tissue formation, and removal of infectious materials) [26].

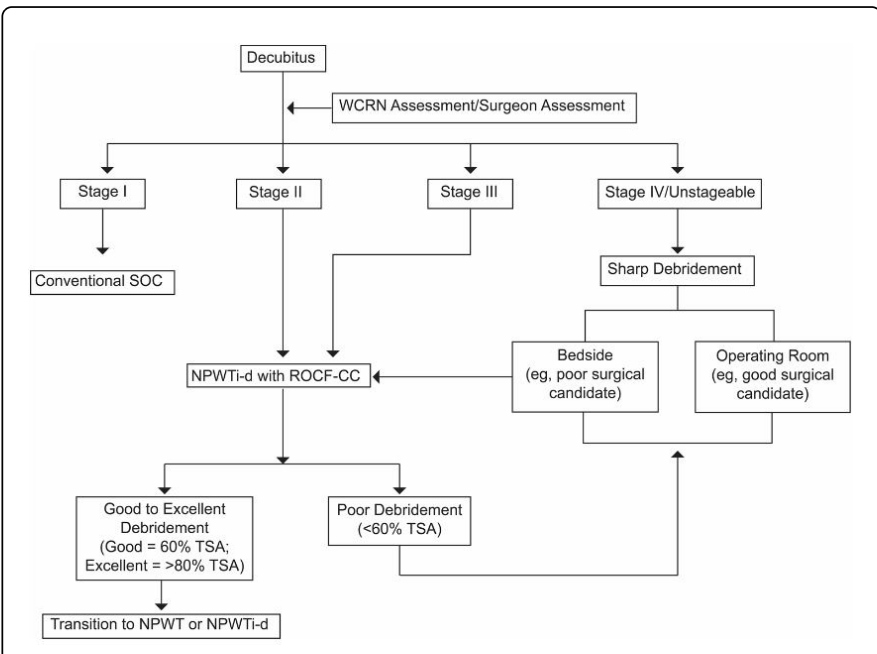

Figure 1: Prospective algorithm (NPWTi-d: negative pressure wound therapy with instillation and a dwell time; ROCF-CC: reticulated open cell foam with through holes; TSA: Total Surface Area; NPWT: Negative Pressure Wound Therapy).

Debridement was performed, when possible, prior to use of NPWTi-d with ROCF-CC, and the periwound area was protected, as needed. The ROCF-CC wound contact layer with $1.0 \mathrm{~cm}$ diameter through holes was cut to size and placed in the wound bed. The $8 \mathrm{~mm}$ or $16 \mathrm{~mm}$ thick cover layer was cut and placed over the wound contact layer to fill the wound depth, explored tunnels, and undermined areas. NPWTi-d was initiated to instill saline or a hypochlorous solution with a dwell time of 10 minutes, followed by $2-3$ hours of $-125 \mathrm{mmHg}$ negative pressure. Dressings were changed every 2-3 days.

\section{Results}

Five patients ( 3 females, 2 males) with a mean age of 65.2 years (range: 50-82 years) were treated (Table 1). Patient comorbidities included obesity, diabetes mellitus, hypertension, and peripheral artery disease. After an average of 6 days of therapy (range: 2-9 days), all wounds showed rapid granulation tissue formation. We also observed improved removal of devitalized tissue and subsequent granulation tissue formation in patients receiving hypochlorous solution compared to patients receiving saline during NPWTi-d with ROCF-CC. All patients were transferred to a skilled nursing facility.

\section{Case Studies}

The following are three cases demonstrating the successful use of NPWTi-d with the ROCF-CC dressing.

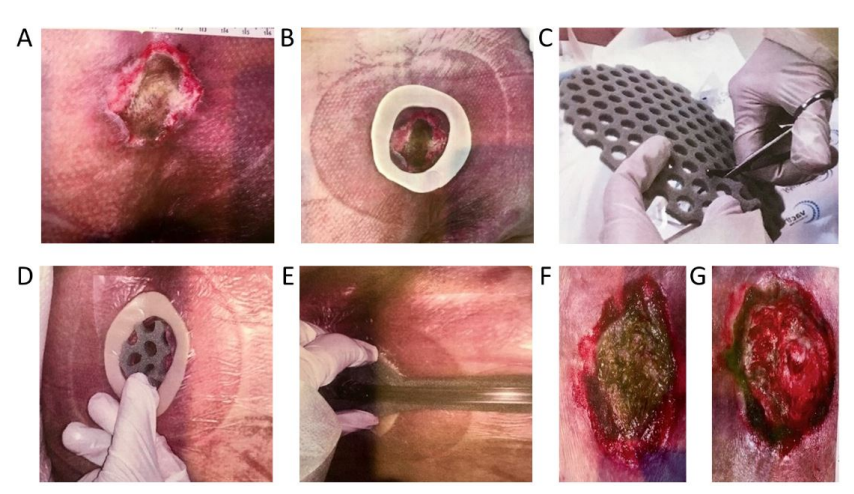

Figure 2: Wound management of coccyx pressure ulcer. A) Wound at presentation. B) Protected wound edges. C) ROCF-CC contact layer cut to fit wound. D) ROCF-CC contact layer applied to wound. E) Dressing applied and NPWTi-d initiated. F) Wound appearance after 3 days of NPWTi-d. G) Wound appearance after 6 days of NPWTi-d.

\section{Case 1}

An 82-year-old female presented with an unstageable coccyx pressure ulcer with $>90 \%$ surface area covered with nonviable tissue (Figure 2A). Medical history included previous small bowel obstruction, Clostridium difficile colitis, incarcerated umbilical hernia, chronic obstructive pulmonary disease, Churg-Strauss syndrome with lung involvement, transverse myelitis, and moderate malnutrition. The wound edges were protected using ostomy paste (Figure $2 \mathrm{~B}$ ), and the ROCF-CC contact layer was cut to fit the wound (Figure 2C). The ROCF-CC contact layer was applied gently to the wound (Figure 2D). The dressing was applied (Figure 2E) and NPWTi-d was initiated (30 cc of hypochlorous solution instilled with a 10-minute dwell time, followed by 2 hours of NPWT at $-125 \mathrm{mmHg}$ ). After 3 days of NPWTi$\mathrm{d}$, the devitalized tissue was semi-liquid (Figure $2 \mathrm{~F}$ ). After 6 days of NPWTi-d, the wound displayed $>90 \%$ viable tissue and the wound 
Citation: Fernandez L, Ellman C, Jackson P (2017) Initial Experience Using a Novel Reticulated Open Cell Foam Dressing with Through Holes during Negative Pressure Wound Therapy with Instillation for Management of Pressure Ulcers. J Trauma Treat 6: 410. doi: $10.4172 / 2167-1222.1000410$

Page 3 of 5

depth decreased (Figure 2G). Standard NPWT was initiated, and the patient was discharged to a long-term acute care facility.

\begin{tabular}{|c|c|c|c|c|}
\hline Case & Age & Sex & Wound etiology & Medical history \\
\hline 1 & 82 & Female & $\begin{array}{l}\text { Unstageable coccyx pressure ulcer; }>90 \% \text { surface } \\
\text { area covered nonviable tissue }\end{array}$ & $\begin{array}{l}\text { Small bowel obstruction; Clostridium difficile colitis; incarcerated } \\
\text { umbilical hernia; chronic obstructive pulmonary disease; Churg- } \\
\text { Strauss syndrome with lung involvement; transverse myelitis; } \\
\text { moderate malnutrition }\end{array}$ \\
\hline 2 & 72 & Male & Unstageable sacral pressure ulcer & Essential hypertension; cerebrovascular accident \\
\hline 3 & 59 & Female & $\begin{array}{l}\text { Stage } 3 \text { pannicular ulcer; } 80 \% \text { devitalized tissue } \\
\text { with foul, purulent drainage }\end{array}$ & Panniculitis; obesity, diabetes mellitus; stomach stapling \\
\hline 4 & 50 & Male & Sacral pressure ulcer with $90 \%$ devitalized tissue & $\begin{array}{l}\text { Motor vehicle accident; acute respiratory failure; } \mathrm{C} 6 / \mathrm{C} 7 \text { fracture/ } \\
\text { spinal cord injury; paralysis }\end{array}$ \\
\hline 5 & 63 & Female & $\begin{array}{l}\text { Thigh pressure ulcer with erythematous border and } \\
100 \% \text { devitalized tissue }\end{array}$ & Active smoker; diabetes mellitus; peripheral artery disease \\
\hline
\end{tabular}

Table 1: Patient demographics and wound etiology.

\section{Case 2}

A 72-year-old male with a history of essential hypertension, cerebrovascular accident, and moderate to severe malnutrition presented with an unstageable sacral pressure ulcer. At presentation, the wound measured $15.0 \mathrm{~cm} \times 11.0 \mathrm{~cm}$ with $>60 \%$ adherent nonviable tissue on the wound surface (Figure 3A). After 24 hours of NPWTi-d (70 cc hypochlorous solution instilled with a 10-minute dwell time, followed by 3 hours of NPWT at $-125 \mathrm{mmHg}$ ), the wound surface filled with $>90 \%$ viable tissue (Figure $3 \mathrm{~B}$ ).
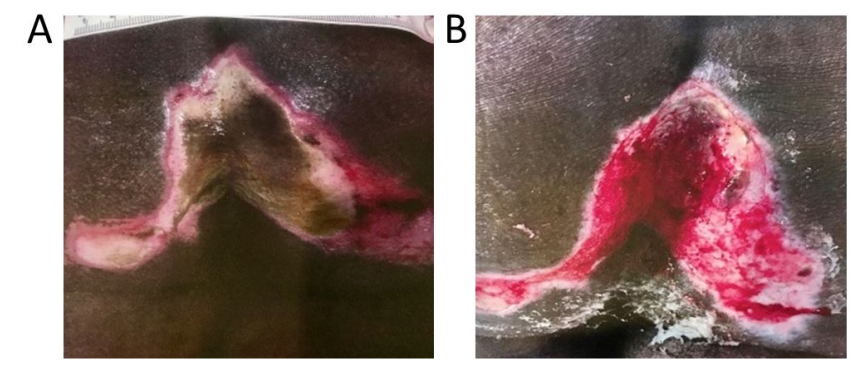

Figure 3: Wound management of sacral pressure ulcer. A) Wound at presentation. B) Wound after 24 hours of NPWTi-d.

\section{Case 3}

A 59-year-old female with a medical history of obesity, diabetes mellitus, and previous stomach stapling presented with panniculitis and a stage 3 panniculus ulcer. The ulcer measured $4 \mathrm{~cm} \times 8.5 \mathrm{~cm} \times 3$ $\mathrm{cm}$ with $80 \%$ devitalized tissue and foul-smelling, purulent discharge (Figure 4A). After 9 days of NPWTi-d (38 cc hypochlorous solution instilled with a 10-minute dwell time, followed by 2 hours of NPWT at $-125 \mathrm{mmHg}$ ), the wound displayed $>90 \%$ viable tissue (Figure $4 \mathrm{~B}$ ).

\section{Discussion}

Pressure ulcers are a serious and costly healthcare issue that can often lead to reduced quality of life for patients $[27,28]$. Interventions to manage pressure ulcers include wound debridement, advanced wound dressings, and advanced wound therapies such as NPWT. However, the advent of NPWTi-d has provided an alternative option for managing these difficult to heal wounds. In our 5 cases, NPWTi-d with ROCF-CC provided effective and rapid removal of the thick exudate and infectious materials and promoted granulation tissue formation in complex wounds.
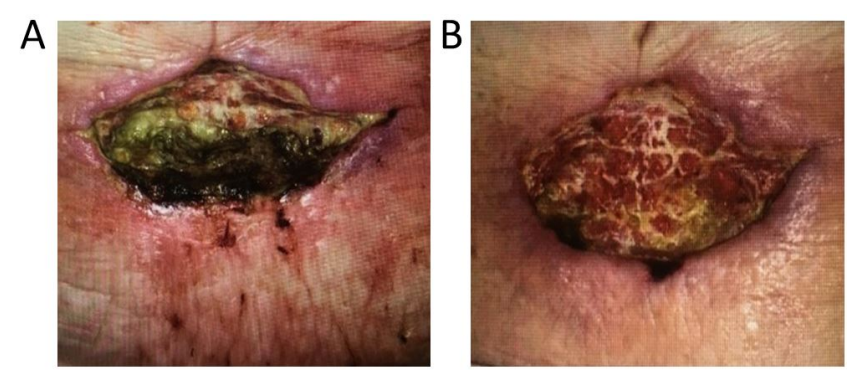

Figure 4: Wound management of pannicular ulcer. A) Wound at presentation. B) Wound after 9 days of NPWTi-d.

At our institution, we developed a preliminary algorithmic approach to managing patients with PrUs (Figure 1) that starts with a patient assessment. Whereas Stage I PrUs are typically treated with conventional standard of care, Stage II and III PrUs may benefit from the use of NPWTi-d with the ROCF-CC dressing, although sharp debridement is required for all Stage IV/Unstageable PrUs. Once there is sufficient debridement with $60 \%-80 \%$ total surface area, then the patients can be transitioned to standard NPWT, which previous studies have demonstrated successful use [29-32], or to NPWTi-d with the standard instillation dressing. As the use of NPWTi-d with ROCFCC dressing continues, our algorithm can be expanded to include other complex patient populations.

The outcomes from our 5 patients are similar to the only other study published on the use of NPWTi-d with the novel ROCF-CC dressing. Teot et al. [25] described their experience with NPWTi-d ROCF-CC in patients with large complex chronic wounds, including PrUs, that contained viscous wound exudate and areas of devitalized tissue. They reported that the ROCF-CC dressing "assisted in loosening, 
Citation: Fernandez L, Ellman C, Jackson P (2017) Initial Experience Using a Novel Reticulated Open Cell Foam Dressing with Through Holes during Negative Pressure Wound Therapy with Instillation for Management of Pressure Ulcers. J Trauma Treat 6: 410. doi: $10.4172 / 2167-1222.1000410$

Page 4 of 5

solubilizing, and detaching viscous exudate, dry fibrin, wet slough, and other infectious materials [25]."

There are still approximately 2.5 million PrUs treated annually in the United States with healthcare costs between $\$ 9.1$ to $\$ 11.6$ billion per year [27]. These costs can be further exacerbated by the elderly population, which is not only the fastest growing segment of the population but also account for the majority of PrUs [33]. The cost of the care for those individuals older than age of 65 contribute a large and growing component of healthcare expenditures. It is estimated that over $40 \%$ of all surgical procedures conducted annually in the United States involve this population group [28,34-36].

Macario [37] has posed the question, "How much does one minute of operating room (OR) time cost?" Recent clinical studies of U.S. hospitals have demonstrated that the average cost per minute of operating room time was $\$ 62[38,39]$. This issue often arises in cases that take more time to complete than usual, or intraoperative delays (more commonly due to personnel, equipment needs/failures), or in surgical procedures conducted in patients with multiple comorbidities, thereby having a higher anesthetic risk and requiring more extensive monitoring and resources in order to conduct the procedure safely.

Therefore, any time trips to the OR can be minimized, healthcare costs of our patients may be potentially impacted. This is especially true for patients, such as ours, that can be described using the term "frailty," a multifactorial state of general physical weakness, often under recognized patient vulnerability and decreased physiologic reserve. Perioperative risk is heterogeneous in this group, as age and comorbidities may fail to accurately predict functional deficits and often cannot adequately predict operative and perioperative morbidity and mortality in this population group [35,40-46].

A recent systematic study by Lin et al. [47] reported that "in patients over 75 years of age, frailty was associated with increased mortality, post-operative complications, prolonged length of stay and discharge to long term care facility." These findings were noted, "irrespective of the type of surgery conducted "and were consistent across different frailty measurement techniques [47]. Currently, the literature investigating frailty and surgery has defined 'geriatric' as those above 60 or 65 years old, and studies in this patient population have recognized frailty being more prevalent with increasing age.

A recent systematic review incorporating 31 studies of frailty in persons 65 years or older found a prevalence from $4.0 \%$ to $17.0 \%$ (mean 9.9\%) of physical frailty, with a higher prevalence when psychosocial frailty was also included $[47,48]$. In our patients, NPWTi$\mathrm{d}$ using the ROCF-CC dressing was selected, as our patients were not candidates for surgical debridement due to their underlying comorbidities contributing to their perceived frailty risk.

\section{Conclusion}

We acknowledge the limitations of our case series, such as the small number of patients, lack of a control group, and selection bias. However, our early experience suggests that the ROCF-CC dressing has unique properties that allowed effective and rapid removal of thick exudate in large complex wounds with substantial areas of devitalized tissue. Also, the dressing was used safely in severely debilitated and frail patients. The use of NPWTi-d with ROCF-CC may potentially decrease cost of care by assisting in bedside wound cleansing and reducing the need for debridement in the OR as well as potentially decreasing morbidity and mortality associated with formal operative surgical intervention. In our clinical practice, NPWTi-d with ROCFCC promoted excellent development of underlying granulation tissue in our 5 patients. Further study is warranted in the use of this novel treatment modality, which will help to more clearly define and inform best evidence-based practice guidelines for its clinical application in the care of patients with chronic complex wounds.

\section{References}

1. National Pressure Ulcer Advisory Panel and European Pressure Ulcer Advisory Panel (2009) Prevention and treatment of pressure ulcers: Clinical practice guideline. National Pressure Ulcer Advisory Panel. Washington DC, USA.

2. Schank JE (2016) The NPUAP meeting - This was no consensus conference. J Am Coll Clin Wound Spec 7: 19-24.

3. Ke Q, Costa M (2006) Hypoxia-inducible factor-1 (HIF-1). Mol Pharmacol 70: 1469-1480.

4. Jones V, Grey JE, Harding KG (2006) Wound dressings. Br Med J 332: 777-780.

5. Stadelmann WK, Digenis AG, Tobin GR (1998) Physiology and healing dynamics of chronic cutaneous wounds. Am J Surg 176: 26S-38S.

6. Thomas S, Andrews A, Jones M, Church J (1999) Maggots are useful in treating infected or necrotic wounds. Br Med J 318: 807-808.

7. Steed DL (2004) Debridement. Am J Surg 187: 71S-74S.

8. Stephen-Haynes J, Thompson G (2007) The different methods of wound debridement. Br J Community Nurs 12: S6, S8-S10, S12-14, S16.

9. Moues CM, Van Den Bemd GJ, Meerding WJ, Hovius SE (2005) An economic evaluation of the use of TNP on full-thickness wounds. J Wound Care 14: 224-227.

10. Sinha S, Mudge E (2013) The national health-care agenda in relation to negative pressure wound therapy. Br J Community Nurs Suppl: S6, S8, S10-S13

11. Kaplan M, Daly D, Stemkowski S (2009) Early intervention of negative pressure wound therapy utilizing vacuum assisted closure in trauma patients: Impact on hospital length of stay and cost. Adv Skin Wound Care 22: 128-132.

12. Dowsett C, Davis L, Henderson V, Searle R (2012) The economic benefits of negative pressure wound therapy in community-based wound care in the NHS. Int Wound J 9: 544-552.

13. Apelqvist J, Armstrong DG, Lavery LA, Boulton AJ (2008) Resource utilization and economic costs of care based on a randomized trial of vacuum-assisted closure therapy in the treatment of diabetic foot wounds. Am J Surg 195: 782-788.

14. Driver VR, Blume PA (2014) Evaluation of wound care and health-care use costs in patients with diabetic foot ulcers treated with negative pressure wound therapy versus advanced moist wound therapy. J Am Podiatr Med Assoc 104: 147-153.

15. Kim PJ, Attinger CE, Crist BD, Gabriel A, Galiano RD, et al. (2015) Negative pressure wound therapy with instillation: Review of evidence and recommendations. Wounds 27: S2-S19.

16. Gupta S, Gabriel A, Lantis J, Teot L (2016) Clinical recommendations and practical guide for negative pressure wound therapy with instillation. Int Wound J 13: 159-174.

17. Goss SG, Schwartz JA, Facchin F, Avdagic E, Gendics C, et al. (2014) Negative pressure wound therapy with instillation (NPWTi) better reduces post-debridement bioburden in chronically infected lower extremity wounds than NPWT alone. J Am Coll Clin Wound Spec 4: 74-80.

18. Wolvos $\mathrm{T}$ (2013) The use of negative pressure wound therapy with an automated, volumetric fluid administration: An advancement in wound care. Wounds 25: 75-83. 
Citation: Fernandez L, Ellman C, Jackson P (2017) Initial Experience Using a Novel Reticulated Open Cell Foam Dressing with Through Holes during Negative Pressure Wound Therapy with Instillation for Management of Pressure Ulcers. J Trauma Treat 6: 410. doi: $10.4172 / 2167-1222.1000410$

Page 5 of 5

19. Brinkert D, Ali M, Naud M, Maire N, Trial C, et al. (2013) Negative pressure wound therapy with saline instillation: 131 patient case series. Int Wound J 10: 56-60.

20. Fluieraru S, Bekara F, Naud M, Herlin C, Faure C, et al. (2013) Sterilewater negative pressure instillation therapy for complex wounds and NPWT failures. J Wound Care 22: 293-299.

21. Kim PJ, Attinger CE, Oliver N, Garwood C, Evans KK, et al. (2015) Comparison of outcomes for normal saline and an antiseptic solution for negative-pressure wound therapy with instillation. Plast Reconstr Surg 136: 657e-664e.

22. Kim PJ, Attinger CE, Steinberg JS, Evans KK, Powers KA, et al. (2014) The impact of negative-pressure wound therapy with instillation compared with standard negative-pressure wound therapy: A retrospective, historical, cohort, controlled study. Plast Reconstr Surg 133: 709-716.

23. Gabriel A, Kahn K, Karmy-Jones R (2014) Use of negative pressure wound therapy with automated, volumetric instillation for the treatment of extremity and trunk wounds: clinical outcomes and potential costeffectiveness. Eplasty 14: e41.

24. McKanna M, Geraci J, Hall K, Hauan B, Howell M, et al. (2016) Clinician panel recommendations for use of negative pressure wound therapy with instillation. Ostomy Wound Manage 62: S1-S14.

25. Teot L, Boissiere F, Fluieraru S (2017) Novel foam dressing using negative pressure wound therapy with instillation to remove thick exudate. Int Wound J 14: 842-848.

26. Baharestani M, De Leon J, Mendez-Eastman S (2008) Consensus statement: A practical guide for managing pressure ulcers with negative pressure wound therapy utilizing vacuum-assisted closureunderstanding the treatment algorithm. Adv Skin Wound Care 21: 1-20.

27. Berlowitz D, VanDeusen Lukas C, Parker V, Niederhauser A, Silver J, et al. (2011) Preventing pressure ulcers in hospitals: A toolkit for improving quality of care. MD: Agency for Healthcare Research and Quality. Rockville, USA.

28. National Center for Health Statistics (2010) National Hospital Discharge Survey, 2010. National Center for Health Statistics.

29. Joseph E, Hamori CA, Bergman S, Roaf E, Swann NF, et al. (2000) A prospective, randomized trial of vacuum-assisted closure versus standard therapy of chronic nonhealing wounds. Wounds 12: 60-67.

30. Wild T, Stremitzer S, Hoelzenbein T, Ludwig C, Ohrenberger G (2008) Definition of efficiency in vacuum therapy-a randomized controlled trial comparing Redon drains with V.A.C. Therapy. Int Wound J 5: 641-647.

31. Ford CN, Reinhard ER, Yeh D, Syrek D, De Las MA, et al. (2002) Interim analysis of a prospective, randomized trial of vacuum-assisted closure versus the health point system in the management of pressure ulcers. Ann Plast Surg 49: 55-61.

32. Baharestani MM, Houliston-Otto DB, Barnes S (2008) Early versus late initiation of negative pressure wound therapy: Examining the impact on home care length of stay. Ostomy Wound Manage 54: 48-53.

33. Bhattacharya S, Mishra RK (2015) Pressure ulcers: Current understanding and newer modalities of treatment. Indian J Plast Surg 48: 4-16.

34. Etzioni DA, Liu JH, Maggard MA, Ko CY (2003) The aging population and its impact on the surgery workforce. Ann Surg 238: 170-177.
35. Walston J, Hadley EC, Ferrucci L, Guralnik JM, Newman AB, et al. (2006) Research agenda for frailty in older adults: Toward a better understanding of physiology and etiology: Summary from the American Geriatrics Society/National Institute on Aging Research Conference on Frailty in Older Adults. J Am Geriatr Soc 54: 991-1001.

36. Stanton MW (2006) The high concentration of U.S. Health care expenditures. Research in Action.

37. Macario A (2010) What does one minute of operating room time cost? J Clin Anesth 22: 233-236.

38. Shippert RD (2005) A study of time-dependent operating room fees and how to save $\$ 100,000$ by using time-saving products. Am J Cos Surg 22: 25-34.

39. Bosco UJ, Peters JA, Torrance A (2016) The elephant in the OR: Improving performance for long surgical cases. Physician Leadersh J 3: 8-12.

40. Ravaglia G, Forti P, Lucicesare A, Pisacane N, Rietti E, et al. (2008) Development of an easy prognostic score for frailty outcomes in the aged. Age Ageing 37: 161-166.

41. Institute of Medicine (US) Committee on the Future Health Care Workforce for Older Americans (2008) Retooling for an Aging America: Building the Health Care Workforce.

42. Bettelli G (2010) Anaesthesia for the elderly outpatient: Preoperative assessment and evaluation, anaesthetic technique and postoperative pain management. Current Opinion Anaesthesiol 23: 726-731

43. Fleisher LA, Beckman JA, Brown KA, Calkins H, Chaikof E, et al. (2007) ACC/AHA 2007 Guidelines on perioperative cardiovascular evaluation and care for noncardiac surgery: Executive summary: A report of the American college of cardiology/American heart association task force on practice guidelines (Writing committee to revise the 2002 guidelines on perioperative cardiovascular evaluation for noncardiac surgery): developed in collaboration with the American society of echocardiography, American society of nuclear cardiology, heart rhythm society, society of cardiovascular anesthesiologists, society for cardiovascular angiography and interventions, society for vascular medicine and biology, and society for vascular surgery. Circulation 116: 1971-1996.

44. Deiner S, Silverstein JH (2011) Anesthesia for geriatric patients. Minerva Anestesiol 77: 180-189.

45. El-Haddawi F, Abu-Zidan FM, Jones W (2002) Factors affecting surgical outcome in the elderly at Auckland Hospital. ANZ J Surg 72: 537-541.

46. Makary MA, Segev DL, Pronovost PJ, Syin D, Bandeen-Roche K, et al. (2010) Frailty as a predictor of surgical outcomes in older patients. J Am Coll Surg 210: 901-908.

47. Lin HS, Watts JN, Peel NM, Hubbard RE (2016) Frailty and postoperative outcomes in older surgical patients: A systematic review. BMC Geriatr 16: 157.

48. Collard RM, Boter H, Schoevers RA, Oude Voshaar RC (2012) Prevalence of frailty in community-dwelling older persons: A systematic review. J Am Geriatr Soc 60: 1487-1492. 